\title{
Geochemical Anomaly Characteristics of Cd in Soils around Abandoned Lime Mines: Evidence from Multiple Technical Methods
}

\author{
Lu Wei ${ }^{1,2,3}$, Meichen Wang ${ }^{4,5}$, Guijian Liu 1,3,* and Dun Wu 1,4,* \\ 1 CAS Key Laboratory of Crust Mande Materials and Environment, School of Earth and Space Sciences, \\ University of Science and Technology of China, Hefei 230026, China; weilu101@126.com \\ 2 Geo-Environment Monitoring Institute of Anhui Province, Hefei 230001, China \\ 3 State Key Laboratory of Loess and Quaternary of Geology, Institute of Earth Environment, The Chinese \\ Academy of Sciences, Xi'an 710075, China \\ 4 Exploration Research Institute, Anhui Provincial Bureau of Coal Geology, Hefei 230088, China; \\ mcwang16@163.com \\ 5 School of Resources and Environmental Engineering, Hefei University of Technology, Hefei 230009, China \\ * Correspondence: lgj@ustc.edu.cn (G.L.); wudun@ustc.edu.cn (D.W.)
}

Citation: Wei, L.; Wang, M.; Liu, G.; Wu, D. Geochemical Anomaly Characteristics of $\mathrm{Cd}$ in Soils around Abandoned Lime Mines: Evidence from Multiple Technical Methods. Molecules 2021, 26, 5127. https:// doi.org/10.3390/molecules26175127

Academic Editors: Binglin Guo, Quanzhi Tian and Chuncai Zhou

Received: 20 July 2021

Accepted: 17 August 2021

Published: 24 August 2021

Publisher's Note: MDPI stays neutral with regard to jurisdictional claims in published maps and institutional affiliations.

Copyright: (c) 2021 by the authors. Licensee MDPI, Basel, Switzerland. This article is an open access article distributed under the terms and conditions of the Creative Commons Attribution (CC BY) license (https:// creativecommons.org/licenses/by/ $4.0 /)$.

\begin{abstract}
Lime mines are a potential source of pollution, and the surrounding soil environment is generally at threat, especially in abandoned lime mines. This paper focuses on the study area in eastern Anhui, attempting to analyze whether $\mathrm{Cd}$ enrichment is related to abandoned mines. On the basis of geological investigation, this study systematically used XRD, XRF, GTS and universal Kriging interpolation to determine the distribution law of $\mathrm{Cd}$ in the study area, and evaluated the potential ecological risk of $\mathrm{Cd}$. The results showed that the main mineral types of soil samples of red clastic rock soil parent material ( $\mathrm{RdcPm})$ and soil samples of carbonate soil parent material $(\mathrm{CPm})$ were not completely the same. Correlation analysis showed that $\mathrm{CaO}, \mathrm{MgO}$ and $\mathrm{Cd}$ were positively correlated with the $\mathrm{CPm}$. Human activities led to the accumulation of $\mathrm{Cd}$ in the study area. High $\mathrm{Cd}$ was mainly concentrated in the northwest of the study area, which was correlated with abandoned mines and soil parent materials. The study area was dominated by slight potential risks, although some areas had medium potential risks and high potential risks. All potential high risks were in the $\mathrm{CPm}$ field. This study provides a scientific basis for the comprehensive utilization and development planning of soil in the study area.
\end{abstract}

Keywords: waste lime mine; $\mathrm{Cd}$; mineral composition; spatial distribution characteristics; potential ecological risk assessment

\section{Introduction}

Ecologically, cadmium (Cd) is one of the most toxic heavy metals, and can have potential adverse effects on soil biological activity, plant metabolism and human health [1]. The naturally occurring $\mathrm{Cd}$ in the soil does not generally pose a hazard to humans. However, $\mathrm{Cd}$ pollution in soil caused by human activities has serious eco-environmental effects [2-4].

According to statistics, in the early 1990s, the area of cultivated land polluted by $\mathrm{Cd}$ in China reached 13,000 $\mathrm{hm}^{2}$, involving 25 areas in 11 provinces (cities). The area of cultivated land polluted by Cd in China has now reached $280,000 \mathrm{hm}^{2}$, and $7 \%$ of the soil Cd concentration exceeds the secondary standard of soil environmental quality, which refers to Cd-polluted soil. Due to rapid economic development, $\mathrm{Cd}$ pollution in the ecological environment has become increasingly serious in many areas due to industrial development and mining [5].

Around the world, the environmental safety risks of $\mathrm{Cd}$ exposure in soil are being given more and more attention. Due to the chemical properties of $\mathrm{Cd}$ and the diversity of pollution sources, it is difficult to conduct scientific investigations on $\mathrm{Cd}$ pollution in soil in 
a region. It is difficult to reflect the concentration and spatial distribution characteristics of $\mathrm{Cd}$ in soil objectively and accurately by collecting and investigating small samples. Assessing the distribution of $\mathrm{Cd}$ in soil has changed from studying a few samples to the spatial distribution characteristics on a regional scale [6]. Based on multiple geo-accumulation indices and correlation and partial redundancy analyses, Li et al. [7] examined the spatial patterns of agricultural soil contaminations for $\mathrm{As}, \mathrm{Pb}, \mathrm{Cd}, \mathrm{Cr}$, and $\mathrm{Ni}$ in the Pearl River Delta, South China, and their relationships with landscape heterogeneity at small, medium and large spatial scales. It was found that distance density variables and land use patterns had stronger influences on trace metal concentrations at a small scale than at a larger scale, whereas the parent materials were important at all the scales. Maas et al. [8] studied the spatial distribution of $\mathrm{Cd}, \mathrm{Cr}, \mathrm{Cu}, \mathrm{Pb}$, and $\mathrm{Zn}$ in 101 sub-surface soils, systematically sampled over a large area around Annaba, the fourth most populous city in Algeria. This approach revealed various anthropogenic pollution sources, more efficiently for large-scale patterns than for local abnormalities.

In recent years, with the implementation of geographic information systems (GIS) and Geostatistics (Geostatis-tics, GTS) in environmental research, the spatial distribution of soil heavy metals has been studied using these methods. McGrath et al. [9] used GTS to study the spatial distribution of soil lead and its risk assessment in the Silvemines region of Ireland. Rodríguez-Martin et al. [10] observed the heavy metal concentration of surface soil in Spanish agricultural regions using multivariate GTS. Wang et al. [11] proposed a spatial analysis method based on land use and carried out a human health risk assessment of heavy metals in soil with this method. Dong et al. [12] used GTS methods to calculate the concentrations of $\mathrm{As}, \mathrm{Hg}, \mathrm{Pb}, \mathrm{Cu}, \mathrm{Cd}, \mathrm{Cr}$ and $\mathrm{Zn}$ in regenerated soil and at different depths of control soils, and carried out an ecological environmental risk assessment of heavy metals.

In eastern Anhui, China, there are a large number of mined and abandoned lime mines, which may impact the surrounding soil environment. Until now, a large amount of soil pollution has been limited to the study of small samples without background parent material difference, although there are few geochemical studies of soil parent materials considering comprehensively large areas. In this paper, the soil around abandoned lime mines was taken as the research object, and the geochemical characteristics and evolution of soil parent materials with different backgrounds are comprehensively considered. The potential ecological risk of soil was evaluated to provide a scientific theoretical basis for the comprehensive utilization and development planning of soil in the study area.

\section{Materials and Methods}

\subsection{Sample Collection}

The method of collecting surface soil samples in this study is implemented with reference to the relevant methods and technical requirements in the Standards of Geochemistry Evaluation of Land Quality (DZ/T0295-2016), Technical Requirements for Regional Eco-geochemical Evaluation (DD2005-02), and Specifications for Multi-objective Regional Geochemical Investigation (DZ/T 0258-2014).

Anhui Province is a typical agricultural province in eastern China and is rich in mineral resources. The study area was located in the east of Anhui Province (Figure 1), and belonged to the agricultural area of the Jianghuai undulating plain. The sampling density was 4-16 points per square kilometer, and the basic sampling density was 9 points per square kilometer. The total sampling area was $18.76 \mathrm{~km}^{2}$, and 80 surface soil samples were collected in two soil parent material types (RdcPm and CPm). 


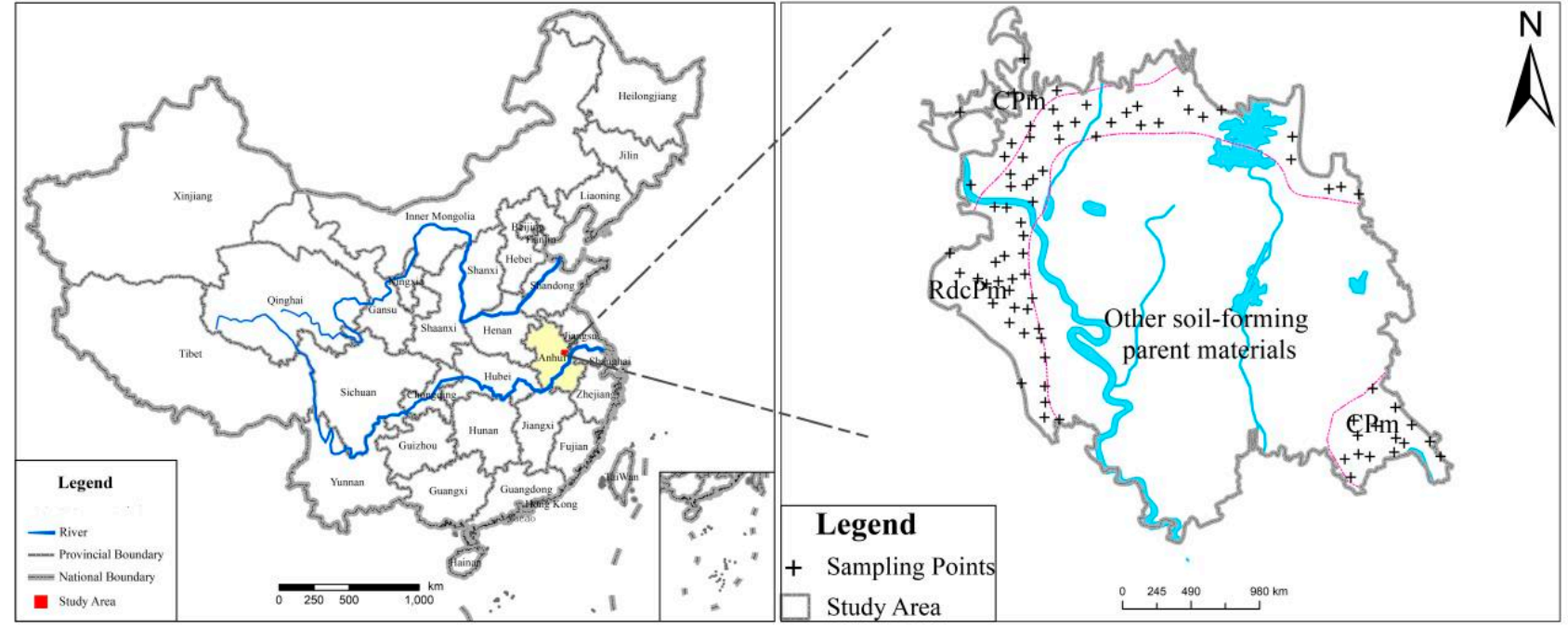

Figure 1. Geographical location of the study area and spatial distribution of sampling points.

\subsection{Sample Preparation}

After the collected soil samples were dried and impurities were removed, $500 \mathrm{~g}$ of block soil samples was ground and sieved to obtain powder samples with a soil particle size of 200 mesh, and the powder samples were stored for later use.

The abandoned lime mine had a mining history of more than ten years, and it had been abandoned for five years.

\subsection{Analytical Method}

The experimental concentrations of this study mainly included the material composition test (XRD and XRF) of soil, soil sample microstructure and cadmium concentration. The purpose of each experiment and the logical relationships between them are shown in Figure 2.

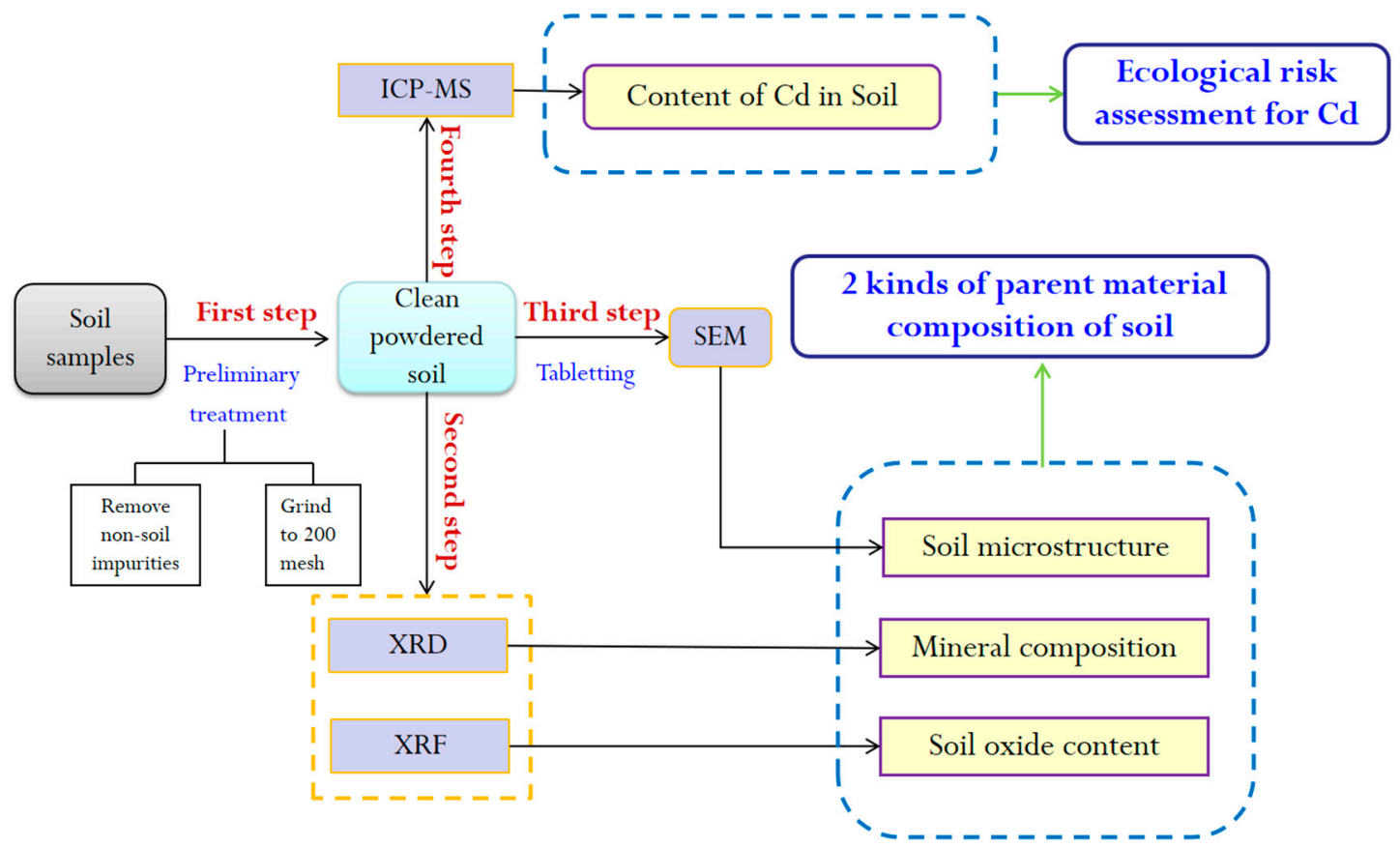

Figure 2. The experimental flow chart of this study. XRD: X-ray diffraction; XRF: X-ray fluorescence; ICP-MS: Inductively coupled plasma mass spectrometry; SEM: Scanning electron microscopy. 


\subsubsection{XRD Measurement}

An X-ray diffractometer (XRD) was used to test the mineral composition in soil samples. A Philips X'Pert PRO XRD was used to record X-ray intensities scattered from the soil samples. $\mathrm{Cu}-\mathrm{K} \alpha$ radiation $(30 \mathrm{kV}, 160 \mathrm{~mA})$ was used as the $\mathrm{X}$-ray source. Powdered soil samples were packed into a rectangular cavity in an aluminum holder and scanned from $0^{\circ}$ to $70^{\circ}$ in the $2 \theta$ range, with a $0.1^{\circ}$ step interval and a $2 \mathrm{~s} /$ step counter time.

\subsubsection{XRF Measurement}

In order to obtain the concentration of the main elements in samples, XRF analysis was performed. The instrument used for XRF analysis of soil samples in this study was XRF-1800 of SHIMADZU Company, Toykoy, Japan. An X-ray tube with Rh target, tube pressure $-60 \mathrm{KV}(\mathrm{Max})$, detection element range $-4(\mathrm{Be})-(92(\mathrm{U})$, detection concentration range $-10^{-6}-100 \%$, minimum analysis area diameter $-250 \mu \mathrm{m}$ was utilized.

\subsubsection{SEM Observation}

In order to obtain the microstructure of soil samples, a JSM-6490LV scanning electron microscope was used to observe the surface morphology of soil samples. Before observation, Ar ion polishing technology was used to treat the surface of soil samples.

\subsubsection{ICP-MS Analysis}

In this study, the concentration of $\mathrm{Cd}$ in soil samples was determined by inductively coupled plasma mass spectrometry (ICP-MS). A Thermo X Series II machine was used, and the working conditions were as follows: transmission power $1250 \mathrm{~W}$, cooling gas flow $13 \mathrm{~L} / \mathrm{min}$, auxiliary gas flow $0.75 \mathrm{~L} / \mathrm{min}$, carrier gas flow $0.8 \mathrm{~L} / \mathrm{min}$, sampling speed $1.5 \mathrm{~mL} / \mathrm{min}$, and detector voltage $3850 \mathrm{~V}$. Two standard soil samples (GBW07401 and GBW07402) were prepared for the experiment under the same experimental conditions. The detection limits of the element analysis method are in line with the requirements of the standards, and there was no obvious system error.

\subsubsection{Potential Ecological Risk Assessment}

The potential ecological risk index $\left(E_{r}^{i}\right)$ was first proposed by the famous Swedish geochemist Hakanson [13]; it combines multidisciplinary theories such as environmental science, ecology, and biotoxicology. According to the nature of heavy metal elements and the characteristics of geochemical behaviors such as migration and transformation, the potential hazard degree of various heavy metal elements is quantitatively calculated and graded. This method is one of the most widely used methods in the study of heavy metals in international and domestic sediments (soil). Therefore, this study will use the above method to carry out a potential risk assessment of $\mathrm{Cd}$ in the soil.

The calculation formulas for the potential ecological risk index $\left(E_{r}^{i}\right)$ for single heavy metal elements are:

$$
E_{r}^{i}=T_{r}^{i} \times C_{f}^{i}=T_{r}^{i} \times C_{n}^{i} / B_{n}^{i}
$$

where $T_{r}^{i}$ is the toxicity response coefficient of the heavy metal element $i ; C_{f}^{i}$ is the influence coefficient of the heavy metal element $i ; C_{n}^{i}$ is the measured value of the metal element $i$ in surface sediment $(\mathrm{mg} / \mathrm{kg})$; and $B_{n}^{i}$ is the background reference value $(\mathrm{mg} / \mathrm{kg})$ of the metal element $i$ in the sediment. In addition, the toxicity response coefficient of $\mathrm{Cd}$ is 30 $\left(T_{r}^{i}=30\right)[14]$.

\section{Result and Discussion}

\subsection{Determination of Background Values of Two Types of Soil Parent Materials}

The background value of soil geochemistry is the most basic parameter used in this study, which represents the changes in the composition, concentration and distribution of materials and elements in different types of soil environments in different regions. The background value of element concentration in soil is a product of the natural geological 
cycle and biological cycle. The background value is the standard to judge whether the environmental medium (atmosphere, water, soil, etc.) is polluted or not, and to classify the degree of pollution. As for the concept of background value, different subjects give different expressions according to their research objectives and concentrations. In the field of geology, the "Geochemical Background" term was first used in the discipline of exploration geochemistry. The definition of the geochemical background value in classical exploration geochemistry is "the normal abundance of elements in a mineral-free geological body or the normal variation of element concentration in an area" $[15,16]$.

In the field of soil environmental science, the background value of soil geochemistry is the abundance of some original or quasi-original materials or elements in soil in a certain natural historical period in a certain region or statistical unit. Since the Industrial Revolution, the scope of human activities and the degree of impact on nature has been expanding and deepening; the earth's natural surface media are affected by human activities to varying degrees. Surface soil has become an important sink, continuously accumulating all kinds of pollutants released by human activities. Therefore, the background value of soil geochemistry is an ideal conceptual statistical value, and it is almost impossible to obtain the background concentration of elements by sampling under natural conditions. Based on the above concept, the "soil geochemistry background value" used in this study refers to the concentration of various elements or components in the deep soil $(150 \sim 180 \mathrm{~cm})$ in the quaternary strata, which is not affected by human activities, and has continuity with the surface soil in soil genesis. The background value is usually characterized by statistical characteristic values (arithmetic or geometric mean value, median and standard deviation) of the element or component concentrations.

In this study, the total number of soil samples of red clastic rock soil parent material ( $\mathrm{RdcPm}$ ) was 56. The $\mathrm{Cd}$ concentrations of the above samples were statistically processed and explained by using normality tests [17]. Results showed that the distribution of $\mathrm{Cd}$ was lognormal to the left with a standard deviation of 0.0265 (Figure 3a). The arithmetic mean value $\left(\mathrm{Cd}_{\mathrm{amv}}\right)$ of 56 samples was $0.1158 \mathrm{mg} / \mathrm{kg}$ and the standard deviation was 0.0264 .
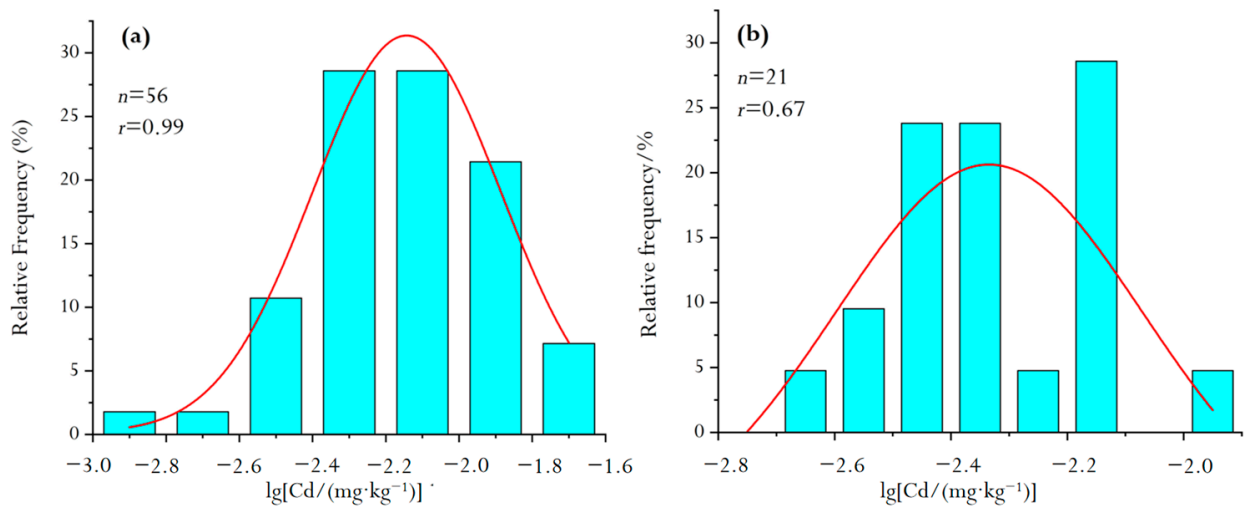

Figure 3. Frequency distribution histogram of $\mathrm{Cd}$ concentration in two soil parent materials. ((a), RdcPm; (b), CPm).

The total number of soil samples of carbonate soil parent material (CPm) was 24 . The normal distribution of $\mathrm{Cd}$ (Figure $3 \mathrm{~b}$ ) could not be obtained by statistical processing of the data and interpretation of the normality test, which indicates that the analyzed sample contains some discrete data. After three cycles the discrete data were eliminated, the remaining samples were reanalyzed, and the results showed that the distribution of $\mathrm{Cd}$ was basically normal. The $\mathrm{Cd}_{\mathrm{amv}}$ of 21 samples was $0.1119 \mathrm{mg} / \mathrm{kg}$ and the standard deviation is 0.0171 .

\subsection{Mineral Composition of Two Types of Soil Parent Materials}

As can be seen from Figure 4, the main mineral components of RdcPm were quartz, illite and montmorillonite; the main mineral components of $\mathrm{CPm}$ were kaolinite, dolomite, 
quartz, illite and calcite. Using Jade 6.0 software, the proportion of minerals could be calculated by fitting the mineral spectra and calculating the peak area (Table 1). From Table 1, it can be seen that quartz accounts for $36.27 \%$ of RdcPm, illite and montmorillonite are the main clay minerals after soil weathering, and carbonate minerals account for $30.8 \%$ of CPm; kaolinite is the main clay mineral, followed by illite. The mineral composition results show that the main mineral types of $\mathrm{RdcPm}$ and $\mathrm{CPm}$ are not identical.
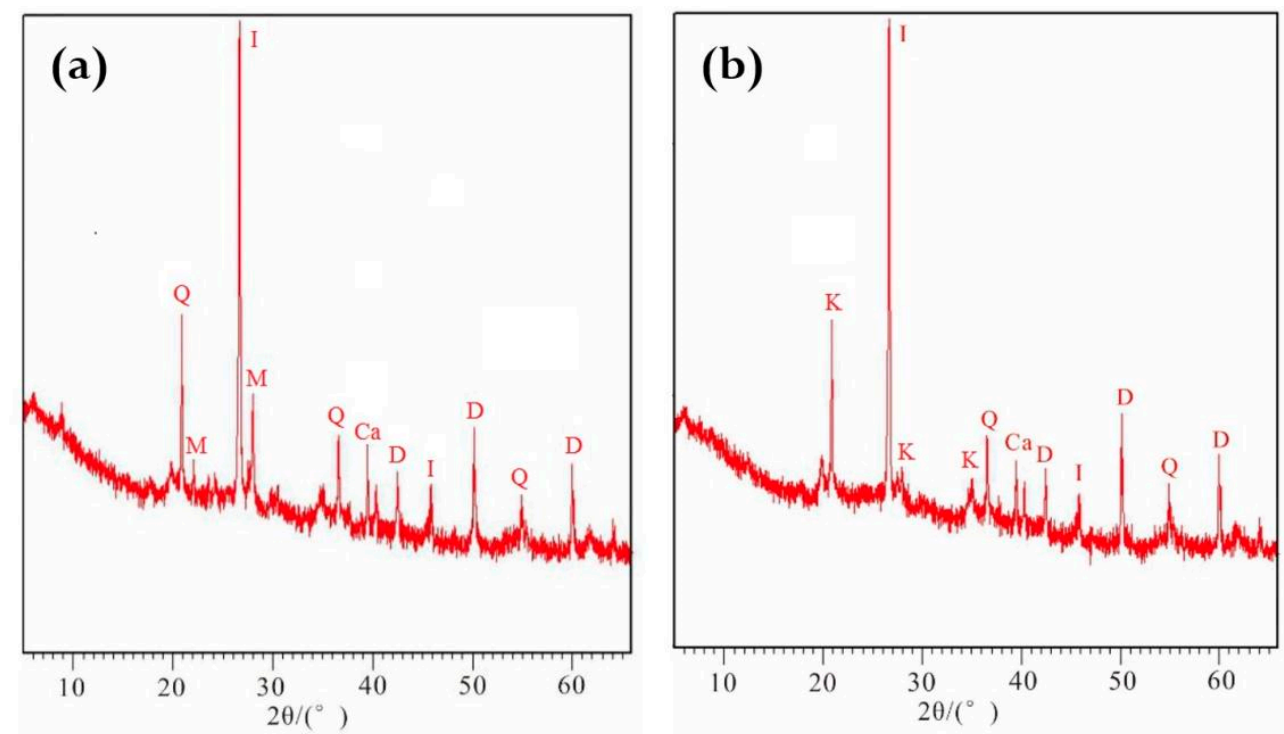

Figure 4. Composition types of minerals in two soil parent materials. (a) RdcPm; (b), CPm. Q: quartz; M: montmorillonite; I: illite; K: kaolinite; Ca: calcite; D: dolomite.

Table 1. Mineral compositions of two soil parent materials.

\begin{tabular}{cccccccc}
\hline \multirow{2}{*}{ Soil Types } & \multirow{2}{*}{$\begin{array}{c}\text { Number of } \\
\text { Statistics }\end{array}$} & Montmorillonite & Illite & Kaolinite & Quartz & Calcite & Dolomite \\
\cline { 3 - 8 } & $n=8$ & 21.90 & 31.25 & NA & 36.27 & 4.75 & 5.83 \\
RdcPm & $n=6$ & NA $^{*}$ & 19.24 & 27.15 & 22.81 & 7.68 & 23.12 \\
CPm & $n$ & &
\end{tabular}

NA*: Not analyzed.

In order to determine whether there was a relationship between the mineral composition and the $\mathrm{Cd}$ concentration in the soil, the oxide concentration of the two soil parent materials was determined in this study (Table 2), and the correlations between the concentrations of $\mathrm{SiO}_{2}, \mathrm{MgO}, \mathrm{CaO}$ and $\mathrm{Cd}$ were determined by correlation analysis (Table 3). The differences in $\mathrm{Cd}$ concentrations in soil were mainly caused by the soil mineral compositions. It can be seen from Table 3 that $\mathrm{Cd}$ is positively correlated with $\mathrm{MgO}$ and $\mathrm{CaO}$ (0.01 level) and negatively correlated with $\mathrm{SiO}_{2}$ in $\mathrm{CPm}$. However, there was a significant positive correlation ( 0.05 level) between $\mathrm{Cd}$ and $\mathrm{MgO}, \mathrm{CaO}$, but not $\mathrm{SiO}_{2}$ in $\mathrm{RdcPm}$. The correlation between $\mathrm{Cd}$ and $\mathrm{MgO}, \mathrm{CaO}$ in $\mathrm{CPm}$ is more obvious, which is mainly due to the interaction between $\mathrm{CO}_{2}$ and water; the main products of carbonate weathering are $\mathrm{MgO}$, and $\mathrm{CaO}$, and precipitated $\mathrm{Ca}^{2+}$ precipitates again to form $\mathrm{CaCO}_{3}[18]$, and $\mathrm{Cd}^{2+}$ can combine with $\mathrm{CO}_{3}{ }^{2-}$ to form insoluble $\mathrm{CdCO}_{3}$. 
Table 2. Percentage contents of oxides in two soil parent materials.

\begin{tabular}{ccccccc}
\hline \multirow{2}{*}{$\begin{array}{c}\text { Soil } \\
\text { Types }\end{array}$} & \multirow{2}{*}{$\begin{array}{c}\text { Number of } \\
\text { Statistics }\end{array}$} & $\mathbf{S i O}_{2}$ & $\mathbf{M g O}$ & $\mathbf{C a O}$ & $\mathbf{M g O}+\mathbf{C a O}$ & Other Oxides \\
\cline { 3 - 7 } & $n=56$ & 70.23 & 0.63 & 0.65 & 1.28 & 28.49 \\
RdcPm & $n=24$ & 62.16 & 1.57 & 4.81 & 6.38 & 31.46 \\
\hline
\end{tabular}

The contents of other oxides were obtained according to $100-\left(\mathrm{SiO}_{2}+\mathrm{CaO}+\mathrm{MgO}\right)$.

Table 3. Correlation analysis between Cd element and oxide in soil.

\begin{tabular}{cccccc}
\hline Soil Types & $\begin{array}{c}\text { Number of } \\
\text { Statistics }\end{array}$ & $\mathrm{Cd}$ & $\mathrm{SiO}_{2}$ & $\mathbf{M g O}$ & $\mathrm{CaO}$ \\
\hline $\mathrm{RdcPm}$ & $n=56$ & 1 & -0.17 & 0.324 & $0.328^{*}$ \\
$\mathrm{CPm}$ & $n=24$ & 1 & $-0.549^{* *}$ & $0.645^{* *}$ & $0.675^{* *}$ \\
\hline
\end{tabular}

${ }_{* *}$ There was a significant correlation at the 0.01 level (bilateral). ${ }^{*}$ There was a significant correlation at the 0.05 level (bilateral).

\subsection{Microstructure of Two Types of Soil Parent Materials}

The microstructure of soil influences and controls its engineering geological characteristics [19]. In view of the differences in mineral composition between the above two types of soil samples, it is necessary to further discuss and perform comparative analyses. In this study, scanning electron microscopy (SEM) was used to describe and analyze the microstructure of the samples [20], as shown in Figure 5. Soil samples were mainly composed of small particles and pores, with large pores distributed locally, showing the microstructure of small particles surrounded by large particles. However, the microstructure of RdcPm samples and CPm samples was obviously different. The RdcPm sample soil particles had rough surfaces and sharp edges and corners. However, the particle surfaces of CPm samples were relatively smooth. In addition, in terms of particle compactness, the particle distribution of the CPm sample was obviously looser than that of the RdcPm sample, and the contact mode between particles of CPm sample was mostly surface-to-surface bonding, whereas other contact modes were less close.
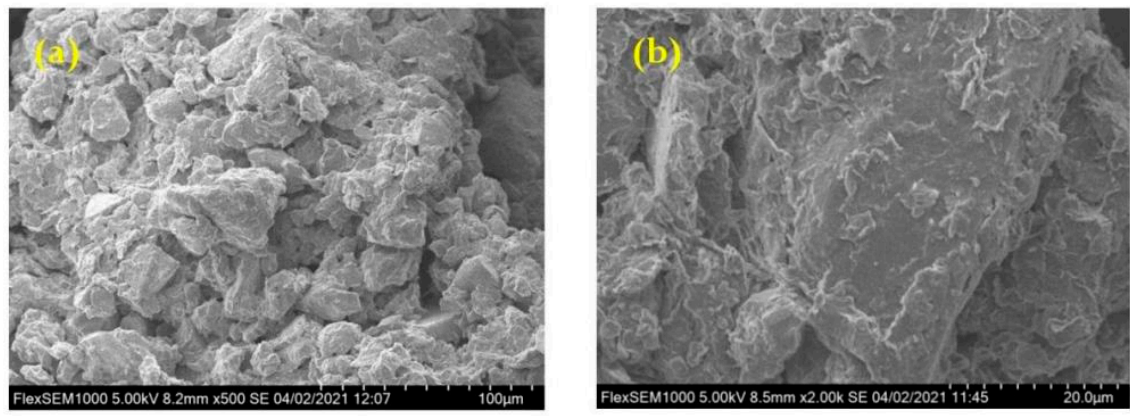

Figure 5. Microstructure characteristics of two soil parent materials: (a) RdcPm; (b) CPm.

\subsection{Spatial Distribution of $\mathrm{Cd}$ in Two Soil Parent Materials}

The $\mathrm{Cd}$ concentration is plotted as a scatter plot in Figure 6. It can be seen from Figure 6 that the $\mathrm{Cd}$ concentration of nearly half of the soil samples in the study area was higher than the background value of the study area, which indicates the influence of human activities on natural $\mathrm{Cd}$ accumulation [21]. Compared with the Chinese soil secondary standard (GB 15618-1995), the Cd concentration in RdcPm was lower (0.3 mg/kg). However, Cd in $\mathrm{CPm}$ was too high locally. This may be due to the concentration of iron and halogen in $\mathrm{CPm}$. This enrichment is not only related to the lithology of carbonate rocks, but also to the strong mineralization of carbonate rock distribution areas [22]. 


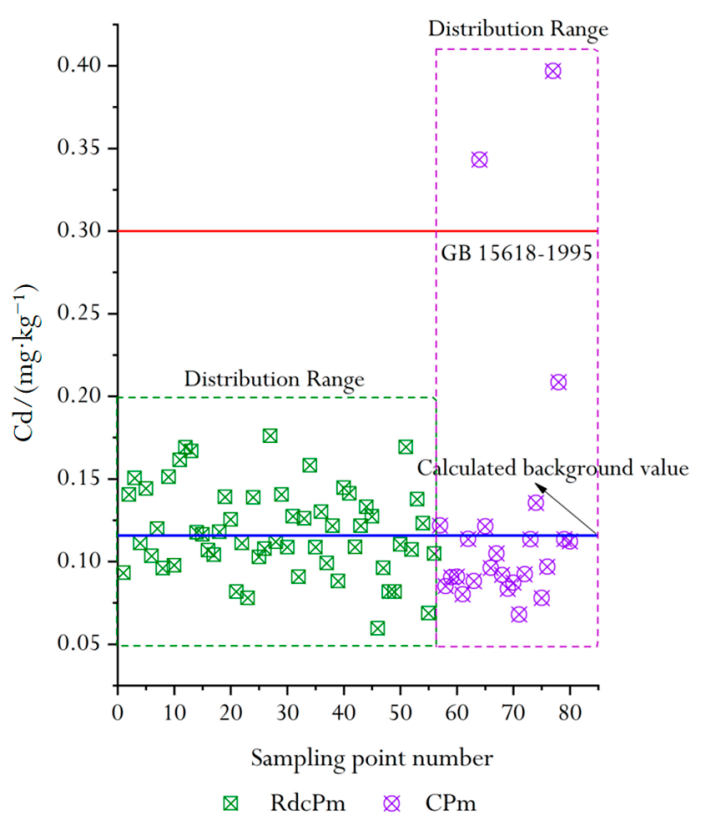

Figure 6. Scatter plot of Cd concentration in two soil parent materials.

In this study, the background value of $\mathrm{Cd}$ in regional soil $(0.0992 \mathrm{mg} / \mathrm{kg})$ and the secondary standard of Chinese soil $(0.3 \mathrm{mg} / \mathrm{kg})$ were taken as the minimum and maximum values for the spatial distribution (STd) evaluation of $\mathrm{Cd}$ in surface soil, respectively. The STd of Cd in the surface soil of the study area was obtained by using the universal Kriging interpolation model [23] in MapGIS software (Figure 7).

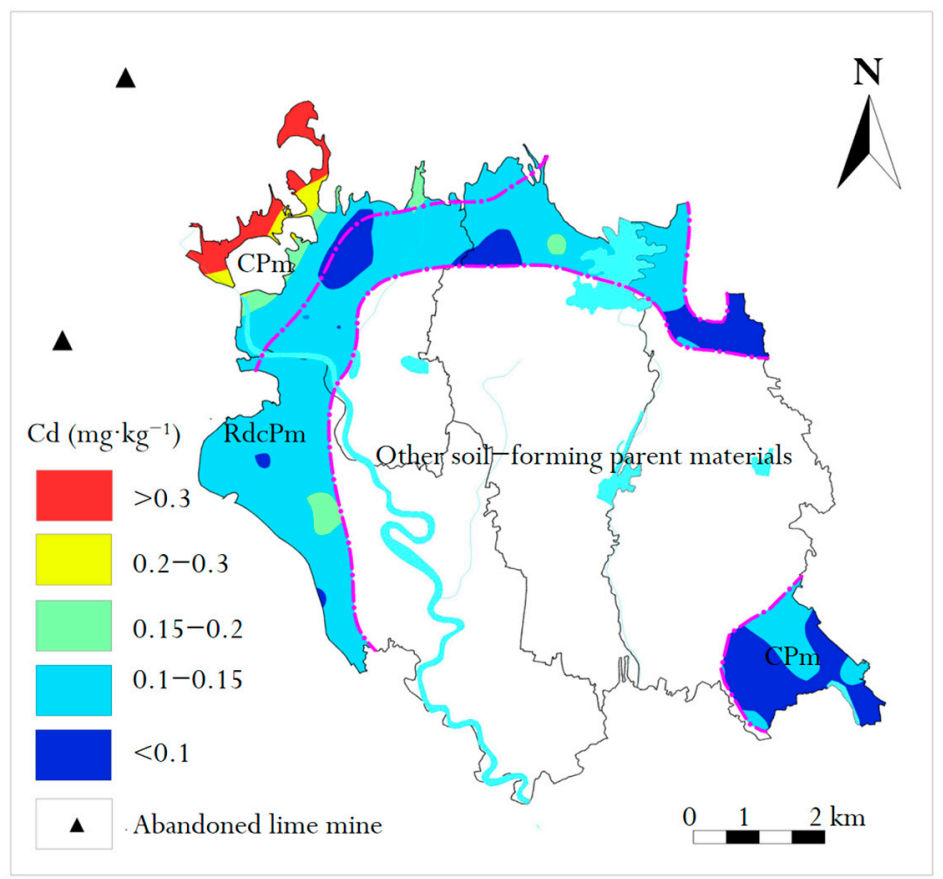

Figure 7. Spatial distribution of $\mathrm{Cd}$ in two soil parent materials.

The STd of Cd in topsoil of the study area was evaluated according to the Chinese secondary soil standard (GB15618-1995). The results showed that the area of $<0.1 \mathrm{mg} / \mathrm{kg}$ was $19.82 \%, 0.1-0.15 \mathrm{mg} / \mathrm{kg}$ was $70.20 \%, 0.15-0.2 \mathrm{mg} / \mathrm{kg}$ was $3.89 \%, 0.2-0.3 \mathrm{mg} / \mathrm{kg}$ was $1.55 \%$ and $>0.3 \mathrm{mg} / \mathrm{kg}$ was $4.54 \%$. The concentration of most samples exceeded the background value $(0.1158 \mathrm{mg} / \mathrm{kg})$, i.e., the concentration of $\mathrm{Cd}$ in most surface soil 
samples was higher than the background value, which indicated the influence of human activities on the accumulation of Cd in natural soil [24]. Compared with GB15618-1995, the concentration of $\mathrm{Cd}$ in the soil in the southeast of the study area did not exceed the standard. The sampling points with greater concentrations than the standard were mainly distributed in the northwest of the research area. It is interesting that the soil parent material type in both regions was $\mathrm{CPm}$. Through site investigation, we found that there were two abandoned open-pit limestone mines in the northwest of the research area. After mining, the mines were abandoned without any environmental protection measures; under certain natural conditions (such as rainfall, wind power, etc.), limestone powder and slag exhibit complex physical chemistry with the surrounding soil, which makes $\mathrm{Ca}^{2+}$ and $\mathrm{Mg}^{2+}$ chelate with the material in the soil particles, and this geochemistry process may have contributed to the enrichment of $\mathrm{Cd}$. This is consistent with the results of Tarnawczyk et al. [25] and Loredo-Portales et al. [26].

\subsection{Potential Ecological Risk Assessment of $\mathrm{Cd}$ in Two Soil Parent Materials}

Based on the analysis of potential ecological risk index $\left(E_{r}^{i}\right)$, the background value of surface soil Cd in two soil parent materials was used as a reference. The potential ecological risk assessment of $\mathrm{Cd}$ on the agricultural quality in surface soil of the study area is presented in Table 4.

Table 4. Potential ecological risk index $\left(E_{r}^{i}\right)$ of surface soil $\mathrm{Cd}$ in the study area.

\begin{tabular}{ccccc}
\hline \multirow{2}{*}{ Soil Types } & \multicolumn{3}{c}{$E_{r}^{i}$} \\
\cline { 2 - 5 } & Min & Max & Ave & Std \\
\hline RdcPm & 16.33 & 69.90 & 32.81 & 9.26 \\
CPm & 16.87 & 206.27 & 43.43 & 32.15 \\
\hline
\end{tabular}

According to two types of soil parent materials, the average concentration of $\mathrm{Cd}$ in the two regions was between 28.0 and 44.0, indicating that the potential ecological risk to agricultural soil is "slight". The maximum Cd value of each region had a significant distribution. In the RdcPm region, the potential ecological risk level of Cd reached "middle". In the CPm region, the value of $C d$ was more than 200, which reached a "strong" potential ecological risk [27].

In order to further show the proportion of potential ecological risk levels of $\mathrm{Cd}$ in two regions, the potential ecological risk index of Cd was interpolated by the universal Kriging method using MapGIS 6.7 software. The spatial potential ecological risk distribution of $\mathrm{Cd}$ is shown in Figure 8.

It can be seen from Figure 8 that $\mathrm{Cd}$ in $\mathrm{RdcPm}$ soil posed a slight risk and middle risk, accounting for $84.65 \%$ and $15.35 \%$, respectively. In CPm soil, Cd was mainly a slight risk, accounting for $84.97 \%$; the slight and medium risks of Cd were $7.05 \%$ and $7.98 \%$, respectively. The data show that $\mathrm{Cd}$ mainly posed a slight potential ecological risk in the study area, and there were a few middle-risk and high-risk areas, whereas high-risk areas only existed in CPm soil (northwest of the study area). On the basis of the above statistical analysis, although the high-risk area was small, there were more medium-risk areas and river systems in the study area. Therefore, it is necessary to study the cause of formation, pollution source and prevention, and control measures of potential ecological risks of $\mathrm{Cd}$ in the study area [28]. As soon as possible, abandoned mine ecological rehabilitation should be performed, to control the potential sources of pollution [29]. Strengthening the study of chemical forms of $\mathrm{Cd}$ in soil [30], understanding the characteristics of soil geochemistry, and performing the targeted remediation of soil pollution should be the goals of future research. 


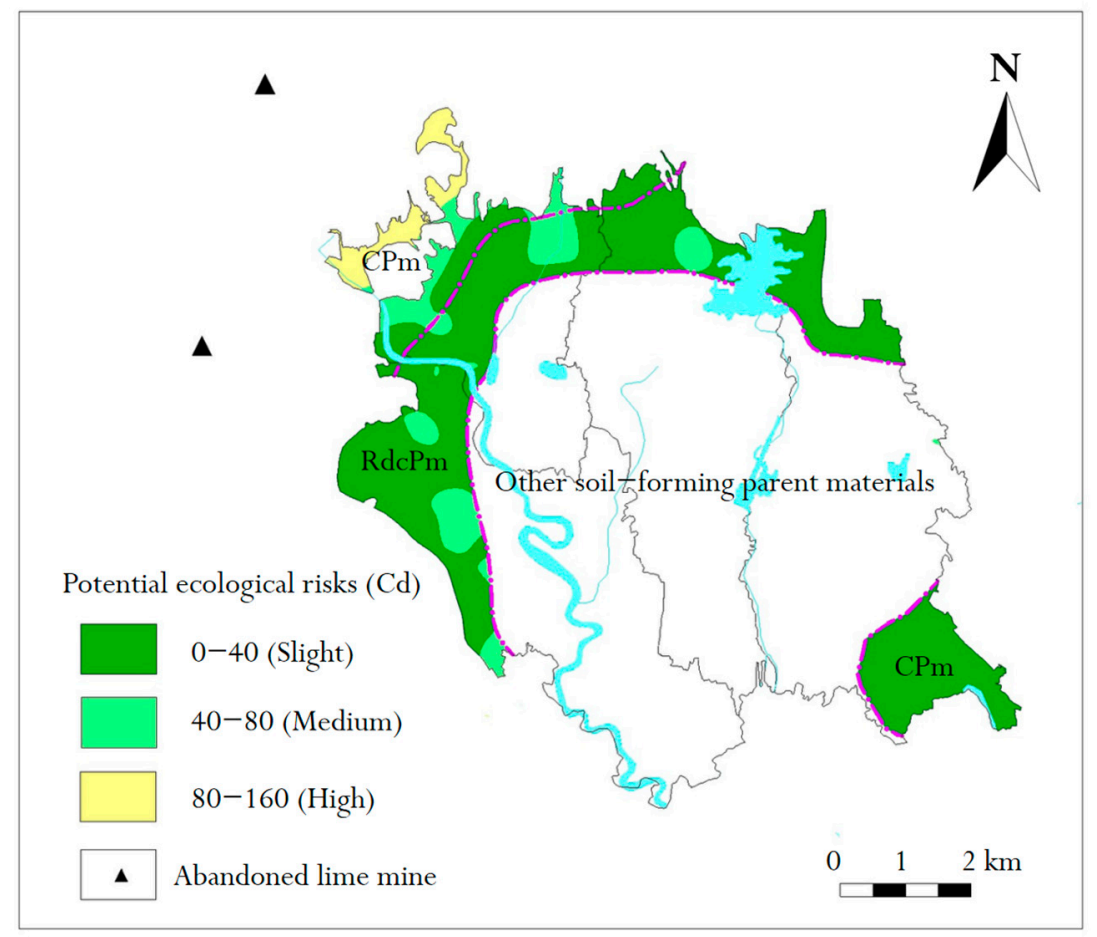

Figure 8. Distribution map of potential ecological risks of two soil parent materials.

\section{Conclusions}

The frequency distribution of sample concentrations in the study area were generally normally distributed. The value of $\mathrm{Cd}_{\mathrm{amv}}$ of $56 \mathrm{RdcPm}$ samples was $0.1158 \mathrm{mg} / \mathrm{kg}$, and the standard deviation was 0.0264 . The $\mathrm{Cd}_{\mathrm{amv}}$ of $21 \mathrm{CPm}$ samples was $0.1119 \mathrm{mg} / \mathrm{kg}$, and the standard deviation was 0.0171 .

Soils with different parent materials have similar pore structures. Soil particles of RdcPm samples have rough surfaces and sharp edges and corners. However, the particle surface of CPm samples is relatively smooth.

The Cd concentrations of nearly half of the soil samples in the study area were higher than the background value of the study area, which indicates that human activities cause $\mathrm{Cd}$ accumulation. High $\mathrm{Cd}$ was mainly concentrated in the northwest of the study area, which was correlated with abandoned mines and soil parent materials.

The study area was dominated by low potential risks, although some areas had medium potential risks and high potential risks. Additionally, all potentially high risks were in the CPm area.

Author Contributions: Conceptualization and writing—original draft preparation, L.W.; Formal analysis, M.W.; Methodology, G.L.; Investigation, L.W.; Software, D.W.; writing-review and editing, D.W. All authors have read and agreed to the published version of the manuscript.

Funding: This study was supported by the Key Research and Development Projects in Anhui Porvince (202104i07020008, 202004g01020006) and the Geochemical Investigation of Soil Quality in Huaihe River Wanjiang Economic Zone (121201236000160009).

Institutional Review Board Statement: Not applicable.

Informed Consent Statement: Not applicable.

Data Availability Statement: The data presented in this study are available in article.

Conflicts of Interest: The authors declare no conflict of interest.

\section{References}

1. Chaney, R.L.; Ryan, J.A.; Li, Y.M.; Brown, S.L. Soil cadmium as a threat to human health. Cadmium Soils Plants 1999, 85, 219-256. 
2. Zhang, J.; Chen, Z.; Zhong, S. Metal (loid)s pollution characteristics and ecotoxicity evaluation in soil nearby a silver smelting yard. Environ. Earth Sci. 2019, 78, 86. [CrossRef]

3. Chen, Y.; Yuan, L.; Xu, C. Accumulation behavior of toxic elements in the soil and plant from Xinzhuangzi reclaimed mining areas, China. Environ. Earth Sci. 2017, 76, 226. [CrossRef]

4. Wushuang, X.; Chi, P.; Hongtao, W. Bioaccessibility and source identification of heavy metals in agricultural soils contaminated by mining activities. Environ. Earth Sci. 2018, 77, 606.

5. Li, M.; Mohamed, I.; Raleve, D. Field evaluation of intensive compost application on Cd fractionation and phytoavailability in a mining-contaminated soil. Environ. Geochem. Health 2016, 38, 1193-1201. [CrossRef]

6. Wei, L.; Liu, G.; Wu, D. Characteristics and provenance of hazardous trace elements in soil from a typical agricultural region in eastern Anhui, China. Geosci. J. 2020, 24, 575-584. [CrossRef]

7. Li, C.; Li, F.; Wu, Z. Effects of landscape heterogeneity on the elevated trace metal concentrations in agricultural soils at multiple scales in the Pearl River Delta, South China. Environ. Pollut. 2015, 206, 264-274. [CrossRef]

8. Maas, S.; Scheifler, R.; Benslama, M. Spatial distribution of heavy metal concentrations in urban, suburban and agricultural soils in a Mediterranean city of Algeria. Environ. Pollut. 2010, 158, 2294-2301. [CrossRef]

9. Mcgrth, D.; Zhang, C.; Carton, O.T. Geostatistical analyses and hazard assessment on soil lead in Silvermines area, Ireland. Environ. Pollut. 2004, 127, 239-248. [CrossRef]

10. Rodríguez-Martin, J.A.; Lopez-Arias, M.; Grau-corbí, J.M. Heavy metals concentrations in agricultural topsoils in the Ebro basin (Spain): Application of the multivariate geostatisticalmethods to study spatial variations. Environ. Pollut. 2006, 144, 1001-1012. [CrossRef]

11. Wang, Z.; Pang, Z.; Guo, Q. Introducing a land-use-based spatial analysis method for human health risk evaluation of soil heavy metals. Environ. Earth Sci. 2013, 70, 3225-3235. [CrossRef]

12. Dong, J.; Yu, M.; Bian, Z. The safety study of heavy metal pollution in wheat planted in reclaimed soil of mining areas in Xuzhou, China. Environ. Earth Sci. 2012, 66, 673-682. [CrossRef]

13. Hakanson, L. An ecological risk index for aquaic pollution con-trol-Asedimento logical approach. Water Res. 1980, 14, 975-978. [CrossRef]

14. Wang, J.; Jiang, Y.; Sun, J. Geochemical transfer of cadmium in river sediments near a lead-zinc smelter. Ecotoxicol. Environ. Saf. 2020, 196, 110529. [CrossRef]

15. Khan, M.; Islam, M.; Salam, A.B.A. Spatial variability and geostatistical analysis of soil properties in the diversified cropping regions of Bangladesh using geographic information system techniques. Appl. Environ. Soil Sci. 2021, 2021, 6639180. [CrossRef]

16. Hawkes, H.E.; Webb, J.S. Geochemistry in mineral exploration. Soil Sci. 1963, 95, 283. [CrossRef]

17. Levinson, A.A. Introduction to Exploration Geochemistry, 2nd ed.; Applied Publishing Ltd.: Wilmette, IL, USA, 1980 ; pp. 1-924.

18. Gaillardet, J.; Calmels, D.; Romero-Mujalli, G. Global climate control on carbonate weathering intensity. Chem. Geol. 2019, 527, 118762. [CrossRef]

19. Yang, G.; Li, H.; Cheng, D.B. Effect soft measurement model of steel slag powder repair heavy metal contaminated soil with fourier transform infrared spectrum. Spectrosc. Spectr. Anal. 2017, 37, 743-748.

20. Rashad, A.M. Investigation on high-volume fly ash pastes modified with micro-size metakaolin subjected to high temperatures. J. Cent. South Univ. 2020, 27, 231-241. [CrossRef]

21. Qiu, M.; Li, T.; Gao, X. Effects of urbanization on Cd accumulation in agricultural soils: From the perspective of accessibility gradient. Sci. Total Environ. 2020, 701, 134799. [CrossRef]

22. Adamu, C.I.; Nganje, T.N.; Edet, A. Major and trace elements pollution of sediments associated with Abandoned Barite Mines in parts of Oban Massif and Mamfe Embayment, S.E. Nigeria. J. Geochem. Explor. 2015, 151, 17-33. [CrossRef]

23. Rufino, M.M.; Albouy, C.; Brind'Amour, A. Which spatial interpolators I should use? A case study applying to marine species. Ecol. Model. 2021, 449, 109501. [CrossRef]

24. Wu, D.; Wang, M.C.; Hu, G. Spatial distribution and environmental assessment of heavy metals in surface soil and ash near industrial sites: A case study. Energy Sources Part A Recovery Util. Environ. Eff. 2021, 1-12. [CrossRef]

25. Tarnawczyk, M.; Uzarowicz, Ł.; Perkowska-Pióro, K. Effect of land reclamation on soil properties, mineralogy and trace-element distribution and availability: The example of technosols developed on the tailing disposal site of an abandoned $\mathrm{Zn}$ and $\mathrm{Pb}$ mine. Minerals 2021, 11, 559. [CrossRef]

26. Loredo-Portales, R.; Bustamante-Arce, J.; González-Villa, H.N. Mobility and accessibility of Zn, Pb, and As in abandoned mine tailings of northwestern Mexico. Environ. Sci. Pollut. Res. 2020, 27, 26605-26620. [CrossRef] [PubMed]

27. Fural, Ş.; Kükrer, S.; Cürebal, İ. Spatial distribution, environmental risk assessment, and source identification of potentially toxic metals in Atikhisar dam, Turkey. Environ. Monit. Assess. 2021, 193, 1-16. [CrossRef]

28. Aiman, U.; Mahmood, A.; Waheed, S. Enrichment, geo-accumulation and risk surveillance of toxic metals for different environmental compartments from Mehmood Booti dumping site, Lahore city, Pakistan. Chemosphere 2016, 144, 2229-2237. [CrossRef]

29. Hu, Z.; Fu, Y.; Xiao, W. Ecological restoration plan for abandoned underground coal mine site in Eastern China. Int. J. Min. Reclam. Environ. 2014, 29, 316-330. [CrossRef]

30. Rassaei, F.; Hoodaji, M.; Abtahi, S.A. Cadmium speciation as influenced by soil water content and zinc and the studies of kinetic modeling in two soils textural classes. Int. Soil Water Conserv. Res. 2020, 8, 286-294. [CrossRef] 